\title{
GAMBARAN TINGKAT PENGETAHUAN IBU- IBU YANG MEMILIKI KEBIASAAN MEROKOK TENTANG KESEHATAN GIGI DAN MULUT TERHADAP OHI-S DI KELURAHAN TANAH MERAH KECAMATAN BINJAI SELATAN
}

\author{
Rosdiana Tiurlan Simaremare \\ Jurusan Keperawatan Gigi Poltekkes Kemenkes Medan
}

\begin{abstract}
Smoking habits can cause poor dental and oral. The knowledge of the mothers about oral and dental health is in low level, it is proven by the poor awareness of the mothers in maintaining their oral and dental hygiene. This study is descriptive research and it is to find out the description of the knowledge level of the mothers having smoking habit about dental and mouth health toward OHI-S in Tanah Merah, South Binjai sub-district. This study is conducted in survey method where the number of the samples is 25 people. The result of the research showed the knowledge level of the smoking mothers about dental and mouth health toward OHI-S in Tanah Merah, South Binjai sub -district that is as follow : 9 people (36\%) are in good category, 16 people $(64 \%)$ are in moderate category and the OHI-S average is 3.4 which is in poor criteria. The conclusion of this research is that the knowledge level of the smoking mothers is in medium category, but the action of maintaining the dental and mouth hygiene is in poor category.
\end{abstract}

Keywords: Mothers' Knowledge, Smoking Habit, OHI-S

\section{PENDAHULUAN}

Kesehatan menurut Organisasi Kesehatan Dunia (WHO) adalah keadaan sejahtera dari badan, jiwa, dan sosial yang memungkinkan setiap orang hidup produktif secara sosial dan ekonomis (WHO, 2016). Dalam pengertian yang luas, sehat adalah suatu keadaan dinamis dimana individu dapat menyesuaikan diri dengan perubahan lingkungan internal (seperti psikologis, intelektual, spiritual, dan penyakit) dan lingkungan eksternal (seperti lingkungan, fisik, sosial, dan ekonomi dalam mempertahankan kesehatannya (Zulfan Saam, 2012).

Menurut Undang-Undang Kesehatan No. 36 tahun 2009 menyatakan untuk mewujudkan derajad kesehatan yang setinggi-tingginya bagi masyarakat, diselenggarakan upaya kesehatan yang terpadu dan menyeluruh dalam bentuk upaya kesehatan perorangan dan upaya kesehatan masyarakat. Upaya kesehatan diselenggarakan dalam bentuk kegiatan dengan pendekatan promotif, preventif, kuratif, dan rehabilitatif yang dilaksanakan secara terpadu, menyeluruh dan berkesinambungan (Depkes RI, 2009).

Kesehatan gigi dan mulut merupakan satu kesatuan dari kesehatan pada umumnya yang tidak dapat dipisahkan satu dengan yang lainnya. Gigi dan mulut merupakan salah satu organ tubuh yang berfungsi sebagai tempat pertama kalinya makanan masuk ke dalam tubuh, sehingga penting bagi kita untuk menjaga kesehatan dan kebersihan gigi dan mulut.Kesehatan gigi dan mulut masyarakat Indonesia merupakan hal yang perlu mendapat perhatian khusus dari tenaga kesehatan, baik dokter maupun perawat gigi. Hal ini terlihat bahwa penyakit gigi dan mulut masih diderita oleh $90 \%$ penduduk Indonesia (Depkes , 2014).

Berdasarkan hasil Survei Kesehatan Rumah Tangga (SKRT) Pada tahun 2011, Departemen Kesehatan RI menunjukkan bahwa penyakit gigi dan mulut termasuk karies dan penyakit periodontal merupakan masalah yang cukup tinggi $(60 \%)$ yang dikeluhkan oleh masyarakat.

Berdasarkan data WHO (2013), prevalensi penduduk usia dewasa yang merokok setiap hari di Indonesia sebesar $29 \%$ yang menempati urutan pertama seAsia Tenggara. Sejalan dengan data hasil survei Global Adults Tobacco Survei (GATS) tahun 2011, Indonesia memiliki jumlah perokok aktif terbanyak dengan prevalensi perokok laki-laki sebesar 67\% (57,6 juta) dan prevalensi perokok wanita sebesar 2,7\% (2,3 juta). Pada tahun 2011, prevalensi merokok lebih tinggi di daerah pedesaan $(37,7 \%)$ dibandingkan dengan daerah perkotaan $(31,9 \%)$. Berdasarkan data Riset Kesehatan Dasar (Riskesdas) tahun 2013, proporsi penduduk umur> 15 tahun yang merokok dan yang mengunyak tembakau cenderung meningkat, berdasarkan Riskesdas 2007 sebesar $34,2 \%$, riskesdas 2010 sebesar 34,7\%, dan Riskesdas 2013 menjadi $36,3 \%$. Proporsi terbanyak perokok aktif setiap hari pada umur 30-34 tahun sebesar 33,4\% dan umur 3539 tahun sebesar $32,2 \%$ yang merupakan penduduk usia produktif. 
Dalam kehidupan sehari-hari sering kali kita menjumpai orang yang merokok di sekitar kita, baik di kantor, di pasar, di tempat umum lainnya atau bahkan di kalangan rumah tangga kita sendiri. Kebiasaan merokok jelas merugikan yang dibuktikan dengan munculnya berbagai artikel yang menyebutkan bahwa merokok dapat membahayakan kesehatan si perokok dan bahkan pada orang di sekitarnya. Telah tersinggung terdahulu bahwa sebatang rokok yang dibakar akan mengeluarkan asap utama yang akan diisap oleh siperokoknya sendiri disebut sebagai perokok aktif, asap sampingan yang akan keluar ke udara dan terisap oleh orang-orang yang ada di sekitar si perokok disebut sebagai perokok pasif.

Berdasarkan uraian diatas, penulis ingin melakukan penelitian untuk mengetahui Gambaran tingkat Pengetahuan Ibu-Ibu yang memiliki kebiasaan merokok tentang Kesehatan Gigi dan Mulut terhadap OHI-S di Kelurahan Tanah Merah Kecamatan Binjai Selatan Tahun 2017.

\section{Tujuan Penelitian \\ Tujuan Umum}

Penelitian ini bertujuan Untuk mengetahui Gambaran tingkat Pengetahuan Ibu-Ibu yang memiliki kebiasaan merokok tentang Kesehatan Gigi dan Mulut terhadap OHI-S di Kelurahan Tanah Merah Kecamatan Binjai Selatan Tahun 2017.

\section{Tujuan Khusus}

1. Untuk mengetahui tingkat pengetahuan Ibu-Ibu yang memiliki kebiasaan merokok di Kelurahan Tanah Merah Kecamatan Binjai Selatan tentang kebersihan gigi dan mulut.

2. Untuk mengetahui Debris Indeks rata-rata pada Ibu-Ibu yang memiliki kebiasaan merokok di Kelurahan Tanah Merah Kecamatan Binjai Selatan tentang kebersihan gigi dan mulut.

3. Untuk mengetahui Kalkulus Indeks rata-rata pada Ibu-Ibu yang memiliki kebiasaan merokok di Kelurahan Tanah Merah Kecamatan Binjai Selatan tentang kebersihan gigi dan mulut.

4. Untuk mengetahui OHI-S rata-rata pada Ibu-Ibu yang memiliki kebiasaan merokok di Kelurahan Tanah Merah Kecamatan Binjai Selatan tentang kebersihan gigi dan mulut.

\section{Manfaat Penelitian}

1. Menambah pengetahuan dan wawasan bagi peneliti

2. Sebagai informasi bagi Ibu-ibu yang memiliki kebiasaan merokok tentang Kesehatan Gigi dan Mulut yang berdampak pada OHI-S di Kelurahan Tanah Merah Kecamatan Binjai Selatan Tahun 2017.

\section{Kerangka Konsep}

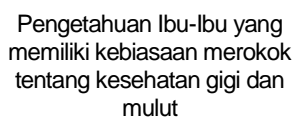

Pengetahuan lbu-lbu yang memiliki kebiasaan merokok tentang kesehatan gigi dan mulut

\section{METODE PENELITIAN}

Jenis penelitian yang digunakan adalah penelitian deskriptif dengan metode survey yang bertujuan untuk mengetahui Gambaran Tingkat Pengetahuan Ibu yang Memiliki Kebiasaan Merokok Tentang Kesehatan Gigi dan Mulut Terhadap OHI-S di Kel. Tanah Merah kec. Binjai Selatan Tahun 2017.

\section{HASIL DAN PEMBAHASAN}

Tabel 4.1

Distribusi Frekuensi Tingkat Pengetahuan Ibu yang Memiliki Kebiasaan Merokok tentang Kesehatan Gigi dan Mulut di Kelurahan Tanah Merah Kecamatan Binjai Selatan Tahun 2017

\begin{tabular}{ccc}
\hline $\begin{array}{c}\text { Kriteria } \\
\text { Pengetahuan }\end{array}$ & $\begin{array}{c}\text { Sampel } \\
(\mathbf{n})\end{array}$ & $\begin{array}{c}\text { Presentase } \\
(\mathbf{\%})\end{array}$ \\
\hline Baik & 9 & 36 \\
Sedang & 16 & 64 \\
Buruk & 0 & 0 \\
\hline Jumlah & $\mathbf{2 5}$ & $\mathbf{1 0 0}$ \\
\hline
\end{tabular}

Dari tabel 4.1 menunjukkan bahwa paling banyak responden memiliki skor pengetahuan dengan kategori sedang, yaitu sebanyak 16 responden $(64 \%)$ sedangkan dengan kategori baik yaitu sebanyak 9 responden (36\%) dan tidak ada responden yang memiliki pengetahuan dengan kategori buruk.

Tabel 4.2

Distribusi Frekuensi Kondisi Kebersihan Gigi dan Mulut (OHI-S) Ibu-Ibu yang Memiliki Kebiasaan Merokok di

Kelurahan Tanah Merah Kecamatan Binjai Selatan

Tahun 2017

\begin{tabular}{cccc}
\hline \multirow{2}{*}{ JUMLAH } & \multicolumn{3}{c}{ Kondisi kebersihan } \\
& gigi & OHI-S \\
& DI & CI & \\
\hline 25 & 2 & 1,9 & 3,4 \\
\hline
\end{tabular}

Berdasarkan tabel 4.2 menunjukkan bahwa pada Ibu-ibu yang memiliki kebiasaan merokok tentang kesehatan gigi dan mulut terhadap OHI-S di Kelurahan Tanah Merah Kecamatan Binjai Selatan tahun 2017 diketahui bahwa OHI-S dengan rata-rata 3,4 dengan kriteria buruk.

\section{PEMBAHASAN}

Berdasarkan hasil penelitian pada tabel 4.1 tingkat pengetahuan Ibu-ibu yang memiliki kebiasaan merokok tentang kesehatan gigi dan mulut terhadap OHI-S di Kelurahan Tanah Merah Kecamatan Binjai selatan menunjukkan 16 responden (64\%) memiliki pengetahuan sedang dan 9 responden (36\%) memiliki pengetahuan baik dan pengetahuan buruk tidak ada. Hal ini mengindikasikan bahwa pengetahuan responden tentang kesehatan gigi dan mulut adalah cukup baik, hal tersebut dapat terjadi karena adanya faktor lain 
yang mempengaruhi pengetahuan responden antara lain tingkat pendidikan, informasi/media massa, sosial budaya dan ekonomi, lingkungan, pengalaman, usia (Notoatmodjo 2010).

Berdasarkan hasil penelitian yang telah dilakukan pada 25 responden di Kelurahan Tanah Merah Kecamatan Binjai Selatan ditemukan 16 responden $(64 \%)$ memiliki pengetahuan yang cukup baik dan 9 responden (36\%) dengan pengetahuan yang baik dan tidak ditemukan responden yang memiliki pengetahuan dengan kategori buruk. Masih ada ditemukan Ibu-Ibu yang tidak mengetahui waktu yang tepat memeriksakan gigi ke dokter gigi dan akibat yang ditimbulkan oleh rokok terhadap lidah. Menurut Rahmadhan A, (2010). Dilakukan Kontrol ke dokter gigi setiap enam bulan sekali, ada atau tanpa ada keluhan. Hal ini dilakukan untuk memeriksa ada atau tidak ada gigi lain yang berlubang. Sehingga dilakukan perawatan sedini mungkin. Selanjutnya untuk melihat, apakah terdapat karang gigi dan kelainan-kelainan yang mungkin terjadi. Menurut Rahcmat H, (2016) Rokok dapat menyebabkan rangsangan pada papilafiliformis (tonjolan pada lidah bagian atas), sehingga perokok sulit merasakan rasa pahit, asin dan manis. Hal itu dikarenakan rusaknya ujung sensoris alat perasa.

Berdasarkan hasil penelitian pada Ibu-ibu yang memiliki kebiasaan merokok tentang status kebersihan gigi dan mulut di Kelurahan Tanah Merah Kecamatan Binjai Selatan diketahui bahwa status kebersihan gigi dan mulut (OHI-S) dengan rata-rata 3,4 dengan kriteria buruk.

Berdasarkan lokasi karang gigi ada dua tempat yaitu di supragingiva atau subgingiva. Kalkulus suprangigival adalah kalkulus yang melekat pada permukaan mahkota gigi mulai dari puncak gingival margin dan dapat dilihat. Kalkulus ini berwarna putih kekuning-kuningan, konsistensinya keras seperti batu tanah liat. Warna kalkulus dapat dipengaruhi oleh pigmen, sisa makanan atau disebabkan oleh rokok. Kalkulus dapat terjadi pada satu gigi, sekelompok gigi atau seluruh gigi dan Kalkulus subgingival adalah kalkulus yang berada dibawah batas gingival margin, biasanya pada daerah saku gusi dan tudak dapat terlihat pada waktu pemeriksaan. Untuk menentukan lokasi dan perluasannya, harus dilakukan probing dengan eksplorer, biasanya padat dan keras.

Warna kalkulus subgingival coklat tua atau hijau kehitam-hitaman konsistensinya seperti kepala korek api dan melekat erat di permukaan gigi ( Putri M. H, Nurjannah,2012). Tindakan atau upaya untuk Pembersihan karang gigi memerlukan bantuan dokter atau perawat gigi yang sering disebut dengan scaling.

\section{KESIMPULAN DAN SARAN}

\section{Kesimpulan}

1. Skor Pengetahuan yang diperoleh dari Ibu-Ibu yang memiliki kebiasaan merokok dengan pengetahuan baik yaitu sebanyak 9 orang $(36 \%)$, kriteria sedang sebanyak 16 orang (64\%) dan kriteria buruk tidak ada. Pengetahuan baik terjadi dalam sikap dan tindakan diikuti dan dilihat keadaan dari Kebersihan Gigi dan Mulut yang buruk, kurang kesadaran untuk menjaga dan memelihara Kesehatan Gigi dan Mulut.

2. Status kebersihan gigi dan mulut (OHI-S) rata-rata 3,4 dengan kriteria buruk. Tindakan yang dilakukan scalling atau pembersihan Karang Gigi dan kontrol ke Dokter Gigi atau Perawat Gigi.

\section{Saran}

1. Diharapkan kepada Ibu-Ibu yang merokok di Kelurahan Tanah Merah Kecamatan Binjai Selatan untuk lebih meningkatkan pengetahuan dan menjaga kebersihan gigi dan mulut.

2. Diharapkan kepada Ibu-Ibu yang merokok di Kelurahan Tanah Merah Kecamatan Binjai Selatan untuk memeriksakan gigi ke dokter gigi tepatnya 6 bulan sekali dan menyikat giginya sesudah merokok agar lebih terjaga kebersihan gigi dan mulut.

\section{DAFTAR PUSTAKA}

Notoatmodjo, S., 2010. Ilmu Perilaku Kesehatan,: Rineka PT Cipta. Jakarta

Notoatmodjo, S., 2010. Metodologi Penelitian Kesehatan, Rineka PT Cipta. Jakarta

Rahmadan, A. G., 2010. Serba-Serbi Kesehatan Gigi dan Mulut,: Jakarta. Bukune

Hongini, S., 2012. Kesehatan Gigi dan Mulut,: Jakarta

Saam, Z., 2012. Psikologi Keperawatan,: PT Raja Grafindo Persada. Jakarta

Putri, M. H, dkk., 2012. Ilmu Pencegahan Penyakit Keras dan Jaringan Pendukung Gigi,: Jakarta. EGC

Yoga, T., 2013. Tuberkulosis, Rokok dan Perempuan,: FKUI. Jakarta

Yoga, T., 2016. Rokok dan Kesehatan,: FKUI. Jakarta

Hidayat, R.,2016. Kesehatan Gigi dan Mulut,: CV Andi Offset. Yogyakarta

http://karyatulisilmiahskripsi.blogspot.co.id/2011/12/12pengaruhkebiasaan-merokok-terhadap.html? $\mathrm{m}=1$

http://webkesehatan.com/merokok-efek-buruk-merokokkesehatan-mulut-gigi/, 4April2016

https://www.google.com/search?q=BAHAYA+ROKOK+ TERHADAP+OHIS 